Published in final edited form as:

Cancer Treat Rev. 2017 April ; 55: 190-199. doi:10.1016/j.ctrv.2017.03.010.

\title{
Immunologic Approaches for the Treatment of Multiple Myeloma
}

\author{
Leo Rasche ${ }^{1}$, Niels Weinhold ${ }^{1}$, Gareth J Morgan ${ }^{1}$, Frits van Rhee ${ }^{1}$, and Faith E Davies ${ }^{1}$ \\ ${ }^{1}$ Myeloma Institute, University of Arkansas for Medical Sciences, Little Rock, AR, USA
}

\begin{abstract}
The FDA approval of two monoclonal antibodies in 2015 has heralded a new era of targeted immunotherapies for multiple myeloma (MM). In this review we discuss the recent approaches using different immunological components to treat MM. In particular, we review current monoclonal antibody based therapies, engineered T- and NK cell products, 'off-target' immunomodulation, and strategies utilizing allogeneic cell transplantation in MM. We discuss how an immunologic approach offers promise for the treatment of this genetically heterogeneous disease, and how patients with acquired drug resistance may particularly benefit from these therapies. We also describe some of the limitations of the current strategies and speculate on the future of personalized immunotherapies for MM.
\end{abstract}

\section{Keywords}

Multiple Myeloma; Immunotherapy; Monoclonal antibodies; Chimeric antigen receptor (CAR) T cells; Checkpoint inhibitors; Allogeneic stem cell transplantation

\section{Introduction and general considerations}

\begin{abstract}
Multiple Myeloma (MM) is characterized by a malignant proliferation of plasma cells in the bone marrow leading to hematopoietic insufficiency and osteolytic bone disease in the majority of patients. Moreover, the excessive production of monoclonal immunoglobulins may lead to harmful tissue deposition resulting in renal failure and/or amyloidosis which effects critical organs such as the heart or kidneys.

MM is not a single disease. On the molecular level at least six different major initiating events have been described leading to deregulation of members of the cyclin D family [1]. Several secondary events, such as chromosomal deletions or $M Y C$ translocations, alter the individual myeloma genome increasing the risk for relapse and poor outcome [2]. Furthermore, substantial intra-patient heterogeneity in mutations and copy number
\end{abstract}

Corresponding author: Dr. Leo Rasche, Myeloma Institute, University of Arkansas for Medical Sciences, 4301 W. Markham Street, \#816, Little Rock, AR, Phone: 501541 3764, Fax: 501526 6162, LRasche@uams.edu.

Conflicts of interest:

LR, NW, and FVR declare no conflicts of interest. GJM served on advisory boards for Amgen, Jansen and Celgene. FED has served on advisory boards for Amgen, BMS, Celgene and Takeda.

Publisher's Disclaimer: This is a PDF file of an unedited manuscript that has been accepted for publication. As a service to our customers we are providing this early version of the manuscript. The manuscript will undergo copyediting, typesetting, and review of the resulting proof before it is published in its final citable form. Please note that during the production process errors may be discovered which could affect the content, and all legal disclaimers that apply to the journal pertain. 
aberrations has recently been reported [3,4]. Thus, the genetic background of MM is highly complex. Of note, this genetic heterogeneity translates to heterogeneous biology and subsequently to heterogeneous clinical outcome when drugs with an intracellular mode of action are used. Importantly the enormous genetic complexity represents one of the main obstacles for the individualization of treatment using therapies targeting mutations or specific signaling pathways.

In contrast, the immunophenotype of MM is considerably more homogenous. Usually, all cells of the MM clone express the monoclonal cytoplasmic immunoglobulin as well as a set of surface receptors potentially targetable with immunotherapeutics. Surface expression levels may differ between individuals and cells [5] but some receptors such as CD138 are usually stably and uniformly expressed even in late disease stages [6]. Moreover, the cytotoxicity of immunotherapy does not typically rely on the induction of tumor apoptosis alone rather on the external lysis of the target cells by granzymes, perforins or complement. Thus, cross resistance to other anti-MM drugs with an intracellular mode of action is unlikely, making immunotherapeutic approaches promising, particularly in patients resistant to conventional MM therapies. In this review, we will discuss the different approaches that we feel are most promising, starting with monoclonal antibodies (mabs), followed by T- and NK cell based approaches, immunomodulation, and finally concluding with aspects of allogeneic stem cell transplantation (Figure 1). Other interesting concepts, such as vaccination approaches including Dendric cell-MM fusions, have not been discussed here as they have been reviewed recently elsewhere [7].

\section{Immunotherapy of MM - a long journey to success}

MM is typically associated with severe immune dysfunction increasing both the risk of infections as well as other secondary malignancies. The former is illustrated by a hazard ratio of 2.2 for developing infections even in patients with the MM precursor disease monoclonal gammopathy of unknown significance (MGUS) [8], the latter by an excess risk for malignancies such as non-melanoma skin cancer or acute myeloid leukemia/ myelodysplastic syndrome in MM patients [9]. Malfunction of components of the innate and adoptive immune system in MM patients has also been described [10-12]. In addition, MM cells can specifically shield themselves from $\mathrm{T}$ cell responses by overexpressing protective molecules such as PD-L1, especially in the context of inflammatory cytokines [13]. Moreover, the pro-inflammatory cytokines IL- 6 and IL-17 trigger MM cell growth and increase the number of immunosuppressive regulatory $\mathrm{T}$ cells (Tregs), resulting in a circulus vitiosus of immune paralysis and tumor progression [14-16]. Many MM patients die from infectious complications originating from both MM treatment and the underlying disease, clearly highlighting that the patient's immune status contributes critically to MM pathogenesis and clinical outcome. As in other cancers, historically enormous efforts have been undertaken to break this vicious circle and to re-engage the immune system to fight the disease. However, success had been variable and in most cases sobering (Figure 2). In the 1990s immune stimulating Interferon alpha was introduced and evaluated in hundreds of MM patients. Although showing some single agent activity [17], considerable toxicity and discordant results in clinical trials limited its wider use [18]. A similar experience was seen with allogeneic hematopoietic cell transplantation, which will be discussed in more detail 
later. Furthermore, in the last 25 years more than 50 mabs have been developed showing anti-MM effects in vitro but these either lacked single agent activity in phase I studies or failed when tested in larger controlled trials [19-21]. As a consequence mab therapy for MM had been considered tricky and impossible for many years, whereas, at the same time the anti-CD20 mab rituximab revolutionized therapy for CD20+ Non Hodgkin B cell lymphoma.

Fortunately, this situation has recently changed and antibodies targeting MM are back in the spotlight highlighted by the FDA's approval of two therapeutic mabs Daratumumab (Dara) and Elotuzumab (Elo) in 2015. Moreover, highly active T cell engaging immunotherapies such as chimeric antigen receptor (CAR) $\mathrm{T}$ cells, bispecific $\mathrm{T}$ cell engaging antibody fragments, as well as checkpoint inhibitors show dramatic responses in other malignant diseases, making the concept of immunotherapy an attractive alternative to chemotherapy in MM.

\section{Monoclonal antibodies targeting SLAMF7 and CD38}

\section{Elotuzumab}

Elotuzumab (HuLuc63, Empliciti®) is a humanized $\operatorname{IgG}_{1}$ class mab targeting the cell surface protein signaling lymphocytic activation molecule F7 (syn. SLAMF7, CS1, CD319, CD2 subset 1, CRACC), a member of the immunoglobulin gene superfamily involved in immune cell activation [22-24]. SLAMF7 can be found in high quantities on the surface of plasma cells and NK cells, as well as on a subset of activated B and T cells whereas other tissues are spared. When evaluated in vitro Elotuzumab exerted its anti-MM activity primarily via antibody dependent cellular cytotoxicity (ADCC). Furthermore, NK cell activation was observed, which could be additionally potentiated with Lenalidomide (Len), resulting in improved ADCC $[25,26]$. In early clinical trials no single agent activity was observed, but some patients experienced long lasting disease stabilization [27]. The knowledge of the synergistic effects with Len in vitro however led to phase I/II studies evaluating the combination of Elotuzumab-Len/dexamethasone (Elo-Rd) in pretreated patients that showed a very promising overall response rate (ORR) of around $90 \%$ (compared to $60 \%$ ORR in historical trials of Rd treatment alone) [28, 29]. Interestingly, the lower dose of $10 \mathrm{mg} / \mathrm{kg}$ body weight achieved a higher ORR than $20 \mathrm{mg} / \mathrm{kg}$ (92 vs 76\%).

The results of the above study led to a randomized phase III trial (ELOQUENT-2) in patients with relapsed and or refractory MM that demonstrated a clear benefit for Elo-Rd therapy with an ORR of $79 \%$ vs $66 \%$ in the Rd control arm with a median time to best response of 2.8 months in both arms. At 2 years, the PFS rates were $41 \%$ for Elo-Rd and $27 \%$ in the control arm, with a median PFS of 19 months versus 14.9 months (HR, 0.7; $P<0.001)$ [30]. Patients who responded to Elo-Rd treatment had a median improvement in time to progression of 4 months. At 3 years, patients in the Elotuzumab arm had a 27\% reduction in risk of progression or death in comparison to Rd alone (HR 0.73; $P=.001$ ) [31].

Importantly, patients with high risk features such as del17p or resistance to the most recent line of therapy also benefited, indicating that the activity of immunotherapeutic approaches are independent of genomic aberrations and related drug resistance mechanisms. These 
results led to FDA approval of Elo in combination with Rd in December 2015. Of note, 94\% of patients enrolled in ELOQUENT-2 were Len naïve. Thus, the clinical activity of the combination in Len exposed patients is unknown, therefore, until further data is available Elo-Rd should preferably be used in Len naïve/sensitive patients.

Promising data has also been obtained with the proteasome-antibody combination, EloBortezomib (Vel)-dexamethasone. Elo-Vel/d was evaluated in relapsed patients and achieved an ORR of $48 \%$ in the phase I trial and an advantageous PFS (9.9 vs 6.8 months) in a randomized phase II trial with half of the patients previously having received Vel therapy $[32,33]$. Similar to Len, in vitro preclinical experiments demonstrated that the combination of Elo-Vel treatment improved ADCC [34].

As of October 2016, a total of 29 studies (Table 1) are registered in the NCI clinical trials database investigating Elotuzumab in all treatment phases of MM. The first reports on multiagent induction therapy showing no major additive side effects or toxicity, and outcome data is eagerly awaited [35,36]. As mentioned above, some immune cells, especially NK and a subset of B and T cells also express SLAMF7 and it has been hypothesized that Elotuzumab-coated effector cells might attack each other, a mechanism termed fratricide. Indeed, lymphocytopenia was reported in some of the randomized studies ( $\geq$ grade 3 in $77 \%$ in Elo-Rd arm vs $49 \%$ in control arm) that may contribute to the higher rate of (viral) infections seen in the mab treated patients ( $81 \%$ vs. $74 \%)$.

In summary, the trials to date clearly show Elotuzumab activity, however, there remain outstanding questions as to where Elo therapy would be most appropriate in the patients' journey (induction vs. maintenance vs. len naïve/resistant relapse). Of note, recent studies have shown lower SLAMF7 expression in patients with ISS stage 3 and progressive disease [37] but it is not known whether reduced expression levels contribute to mab resistance, or indeed whether the level of SLAMF7 expression may act as a surrogate marker of drug sensitivity. Moving forward personalized strategies may incorporate the use of the Fc $\gamma$ receptor (CD16) polymorphism on NK cells, as a recent report showed superior ADCC and a trend for longer PFS in patients expressing high affinity variants [38]

\section{CD38 targeting antibodies}

In contrast to Elotuzumab at least 2 out of the 3 currently reported CD38 targeting mabs show single agent activity in clinical trials inducing complete remissions (CR) even in heavily pretreated patients with refractory disease. Daratumumab (Darzalex ${ }^{\circledR}$, FDA approved since November 2015) reported a remarkable ORR of 36\% including durable CRs beyond 1 year in a dose escalating phase I trial [39], a response rate similar to the one shown for single agent Rituximab in patients with low grade lymphoma [40]. In a phase II trial focusing on dual (IMiDs and PI) refractory disease, single agent Daratumumab still induced an objective response in $29 \%$ of patients including CRs [41]. Of note, as in the Elotuzumab studies, drug refractory status did not negatively impact mab response, once again highlighting the lack of cross resistance to other MM drugs. However, patients with adverse cytogenetics showed a trend to a lower response rate (ORR 20\%). 
In the first preclinical report on Daratumumab the authors explained that it mediated its antiMM effect via complement dependent cytotoxicity (CDC) [42], however, recently several other mechanisms of action have been described including ADCC, antibody-dependent phagocytosis (ADPC), induction of apoptosis, as well as a more indirect immune modulatory effect, mediated by the depletion of suppressive CD38+ Tregs [43-45]. Interestingly, a number of other hematopoetic cells also express CD38 including NK cells, basophils, monocytes, early B cells, activated T cells, erythrocytes and platelets [46, 47]. In the clinical studies NK cells were particularly depleted but numbers recovered after treatment. No correlations were observed between reductions in the number of NK cells and infections [48]. To date adverse events have not limited the therapeutic use of CD38 antibodies, however blood counts should be monitored closely, especially platelets.

Besides Daratumumab, two other CD38 targeting molecules are in clinical development. Isatuximab (SAR650984) showed robust single-agent activity in early clinical trials and MOR03087 demonstrated activity in combination with novel agents or dexamethasone [49]. In vitro studies have shown that the different CD38 mabs rely on different mechanisms of action (e.g., ADCC, ADPC, CDC etc.). For example the activity of MOR03087 is not mediated by $\mathrm{CDC}$, however, it is not clear how or whether these differences in mechanism of action translate into any differences in clinical activity.

Numerous strategies combining CD38 mabs with other MM active drugs are currently under investigation (Table 1) and early results suggest synergistic activity with established compounds. For example, Dara-VelDex resulted in a $100 \%$ ORR when used as induction therapy in newly diagnosed patients, and Dara+Rd had an ORR of $>80 \%$ when used in Lensensitive relapses [50, 51]. In a randomized phase III trial (POLLUX) evaluating the combination $\mathrm{Rd}+/-$ Dara in relapsed or refractory MM the antibody triplet led to $83.2 \%$ PFS at 12 months compared with $60.1 \%$ in the control group, and a median time to best response of 5.1 months [52]. In another randomized trial 498 patients who had relapsed or refractory MM received ether Daratumumab-VelDex or VelDex alone (CASTOR). The 12month PFS rate was $61 \%$ in the Daratumumab arm versus $27 \%$ in the VelDex arm. Infusion related reactions and thrombocytopenia were more common in the triple combination $(45.3 \%$ vs $32.9 \%)$ [53].

It is still unknown whether classical chemotherapy, potentially weakening the immune effector compartment, can be enhanced by mabs. Furthermore, studies investigating the mechanisms leading to mab resistance are warranted. It is known that CD38 expression decreases from initial MM diagnosis through subsequent relapses and that low CD38 expression levels are associated with poor clinical responses [54-56]. However, upregulation of anti-complement receptors CD55 and CD59 seems to be equally important in protecting MM cells from Dara-mediated lysis, again stressing CDC as a major effector mechanism [57]. Interestingly, treatment with all-trans retinoic acid (ATRA) restored CD38 expression in vitro and generally improved Dara efficacy in preclinical models [55, 57]. Therefore, further studies combining CD38 mabs with ATRA and other immune modulatory drugs are warranted to potentially recapture response in Dara-refractory disease. Of note, poor response to single agent Dara is frequently seen in patients presenting with high CD38 expression levels. A potential microenvironment-related resistance mechanism was recently 
described [58]. In vitro ADCC was impaired when MM cell lines were co-cultured with bone marrow stromal cells. This protective effect was mediated by survivin; a phenomenon which had been previously described for other immunotherapeutics [59].

A condition that continues to be difficult to treat is extramedullary disease (EMD). Of 14 EMD patients receiving Dara monotherapy within the MMY2002 trial only 3 responded [41]. In contrast to the well-perfused bone marrow, mab bio-distribution at soft tissue or immune-deprived sites such the central nervous system or testis is decreased and this may contribute to the lower ORR in EMD patients. CD38 expression can also be lost in extramedullary relapse [60]. Moreover, EMD is characterized by high proliferation [6] and it is not currently known whether proliferating high risk disease is susceptible to CD38 mab treatment at all.

\section{Other MM targeting antibodies}

A number of IgG mabs specific to other MM surface targets are currently under investigation, either naked or with the addition of an immunotoxin, with some mabs showing objective responses in early clinical trials. However, when considering the ones with single agent activity (anti-CD40 Lucatumumab, anti-CD138-immunotoxin Indatuximab ravtansine, and anti-CD56-immunotoxin Lorvotuzumab mertansine) response rates were limited to single cases, and dose limiting toxicities were reported making their further development as monotherapy unlikely [61-63]. For Indatuximab ravtansine response rates were higher in combination with $\mathrm{Rd}$ and randomized controlled data is awaited [64]. Other mab-drug conjugates such as GSK2857916 targeting B-cell maturation antigen (BCMA), and ABBV-838 targeting SLAMF7 are still completing dose escalation phase I studies [65-68].

We recently reported that Glucose regulated protein (GRP) 78, a heat shock protein with cell surface expression that is involved in the unfolded protein response, is a promising immunotherapeutic target in MM. The anti-GRP78 IgM mab PAT-SM6 led to disease stabilization as a single agent in phase I, and when used in combination with novel agents induced an objective response in a case of late stage multi-drug resistant MM with extramedullary involvement $[69,70]$.

Generally the concept of mab-based immunotherapies for the treatment of relapsed MM is proven. Interestingly, although single agent activity is desirable, it is not always necessary providing the combination of mab with other drugs exerts robust synergistic clinical activity. The results of the ongoing clinical trials in newly diagnosed patients are eagerly awaited. Hopefully, these studies will not only demonstrate clinical activity but will also help in determining which part of a patients journey mab therapy is most appropriate and which types of MM patients benefit most from therapy.

\section{T cells based approaches}

Autoimmune diseases illustrate the efficacy and specificity of autoreactive T cells to lyse and destroy autologous tissue. Numerous efforts have been undertaken to use T cells to fight malignant disease, and in recent years two main strategies have emerged to engage $T$ cells to attack tumors. In the first, $\mathrm{T}$ cells targeting surface antigens are redirected by chimeric 
antigen receptors (CAR) or bispecific antibody constructs to target the tumor, and in the second autologous tumor reactive/tumor infiltrating $\mathrm{T}$ cells are activated with the help of additional immunotherapeutic agents.

\section{CAR T cells}

CAR T cells (CART) are typically generated by fusing an antigen binding element (usually a single chain variable fragment ( $\mathrm{scFv}$ )) to a $\mathrm{CD} 3 \zeta$ chain anchored in the cell membrane together with co-stimulatory proteins such as CD28 or 4-1BB, enabling intracellular signaling [71]. When recombinantly expressed in patients' $\mathrm{T}$ cells, these artificial, MHCindependent T cell receptors (TCR) are stably incorporated in the membrane, and override inherent TCR functions. This includes both, binding and lysis of targeted cells, as well as T cell proliferation and survival signaling. Compared to ADCC, T cell responses are much more efficient, thus when $\mathrm{T}$ cells are chosen as effectors, the target needs to be selected very carefully as the expression of the target in healthy tissues can lead to serious, even lethal, side effects as was seen in the early CART studies $[72,73]$. Since "real" tumor-specific antigens are rare or only heterogeneously expressed [74], to date most attempts have focused on tissue- or lineage-specific markers such as the B lymphocyte antigen CD19. Treatment with CD19 directed CARTs has led to remarkable responses including durable CRs in patients with CD19 positive lymphomas and leukemias even at late and refractory disease stages $[75,76]$.

MM cells typically lack CD19 expression [77], however, in a series of 655 patients evaluated within the PETHEMA/GEM study group at least 4\% of cases showed CD19 expression, with expression being associated with impaired outcome [78]. A similar incidence and relation to poor outcome was recently described for CD19/CD81 dual positive MM in another set of patients [5]. Of note, the amount of antigen expression sufficient for $\mathrm{T}$ cell activation and response may be considerably lower than the sensitivity of the techniques used to determine expression in routine practice, e.g., flow cytometry [79]. Thus, the proportion of patients with a sufficient amount of CD19 expression, suitable for CART therapy could be higher than $4 \%$. Recently Garfall et al. observed a long lasting complete remission in a relapsed MM patient who was treated with CD19+ CARTs in the context of an autologous stem cell transplant (ASCT) [80]. The patient had a previous ASCT without CARTs and relapsed quickly. Since MM cells in the investigated patient showed little/no CD19 expression the authors speculated that possible CD19+ precursor MM cells were eliminated by the CARTs. Unfortunately, updated information on further patients from this study lowered expectations with only one further objective response [81]. CD19 directed T cell therapy in MM as well as lymphoma and leukemia is not without toxicity. B cell depletion leads to hypogammaglobulinemia and increased risk of infectious complications. Unexplained encephalopathy occurs in $20 \%$ of CD19 directed CART treated patients [82, 83]. Moreover, expansion of $T$ cells is orchestrated by the release of cytokines which in overwhelming concentrations can lead to capillary leakage with septic shock like symptoms requiring vasopressors and intensive care. This cytokine release syndrome (CRS) is unpredictable both in severity and timing [84]. 
Kochenderfer et al. recently reported a phase I trial investigating a single infusion of antiBCMA CARTs in patients with late stage MM following a short course of cyclophosphamide and fludarabine conditioning. In cohorts treated with up to $1 \times 10^{6}$ cells $/ \mathrm{kg}$ bodyweight some preliminary responses (mainly stable disease, 1 transient partial response (PR)) were observed, whereas at 3 and $9 \times 10^{6} / \mathrm{kg}$, three out of five heavily pretreated patients responded rapidly (1 CR and 2 very good PR) $[85,86]$. Of note, the infused number of CART was extremely high and all 3 responders developed CRS and the conditioning with fludarabine and cyclophosphamide induced prolonged aplasias in some patients. CARTs targeting the $x$ light chain have also been evaluated using a basket phase I study design including $\kappa$-positive hematological malignancies. Of 7 patients with $\kappa \mathrm{MM}, 4$ had stable disease lasting 2-17 months and no specific toxicities to the $\mathrm{T}$ cell product were observed [87]. In another pilot study using redirected $\mathrm{T}$ cells with affinity-enhanced TCRs recognizing NY-ESO, a cancer testis antigen heterogeneously expressed in up to $60 \%$ of advanced myelomas, objective responses were seen in 18 out of 20 NY-ESO positive cases. However, $\mathrm{T}$ cell transfer was also conditioned with high-dose melphalan and ASCT, which may explain some of the high response rates [88]. When patients progressed, they either lost NYESO expression or the modified $\mathrm{T}$ cell graft itself, further suggesting biological activity of the product. It is important to note that T cells with affinity-enhanced TCRs bind to peptides processed and presented in a certain MHC complex, which may limit this approach to patients with the most common MHC types. These studies, however, clearly illustrate the power of T cells to lyse MM cells and may be the first step towards chemo-free treatments for MM. A number of other targeted CART cell approaches are currently being investigated in the preclinical stage including CD38 and CS-1 $[89,90]$.

\section{Bispecific antibodies or CARTs?}

An alternate approach to redirecting $\mathrm{T}$ cells to tumors is achieved with bispecific antibodies. While one fragment binds to a tumor surface antigen another simultaneously engages $\mathrm{T}$ cells via CD3. Multiple constructs have been developed bringing $\mathrm{T}$ cells and tumor cells in close proximity, leading to both lysis of the target and proliferation of the effector (T) cell. The main advantage of bispecifics in comparison to CARTs is the significantly less time and infrastructure needed for their preparation as they are potentially an 'off the shelf' product. The generation of CARTs requires a cell separation step, an in vitro transfection and expansion step, shipping, and finally reinfusion of the cell product, whereas, bispecifics can be easily stored and immediately administered under standard conditions allowing their evaluation in large clinical trials. As a consequence, the first FDA approved specific $\mathrm{T}$ cell immunotherapy is blinatumumab - a BiTE-type bispecific construct efficiently targeting CD19 positive ALL [91, 92]. Furthermore, the management of toxicity appears to be less challenging as $\mathrm{T}$ cell activity can simply be halted by discontinuing the infusion. The main disadvantage however of this backbone approach is the in situ activation of autologous $\mathrm{T}$ cells. Recent analysis suggests unwanted stimulation of immune suppressive Tregs, which also carry the CD3 molecule, leading to therapy resistance particularly in patients with baseline increased Treg numbers [93]. Of note, Treg frequencies are generally increased in MM [16]. Moreover, multiple chemotherapies significantly impair $\mathrm{T}$ cell function and consequently may impact the activity of bispecifics in pretreated patients [94]. Indeed, in ALL resistance to blinatumumab was seen more often than resistance to CD19-CART 
treatment $(42 \%$ vs $70-90 \%$, ) although there is no prospective randomized data comparing the two modalities [93].

In MM BCMA/CD3 bispecific constructs have been developed and show promising activity in preclinical models with one molecule (BI 836909) already commencing the dose escalation part of a phase I study [95-97]. Other targets addressed with bispecific antibodies include CD38 [98], CD138 [99], CD20 [100], and Wue-1 [101].

\section{Activation of myeloma infiltrating $\mathrm{T}$ cells}

Another therapeutic strategy focuses on the activation of already existing tumor immunity, particularly on rousing dormant tumor infiltrating T cells. MM cells as well as cells from the microenvironment can protect themselves from immune responses through expression of inhibitory ligands such as programmed death receptor ligand 1 (PD-L1) [102]. Blockage of PDL-1 as well as inhibition of PD1 on T cells leads to activation of tumor infiltrating T cells specific for a variety of individual tumor antigens. Proof of principle was recently shown for a number of checkpoint inhibitors including Pembrolizumab, and Nivulomab, which induced remarkable single agent activity in tumors with a high mutational load such as smokingassociated lung cancer or malignant melanoma [103]. In MM initial studies were disappointing as no objective responses were seen [104]. However, in combination with Len or Pomalidomide heavily pre-treated and refractory patients responded $[105,106]$, leading to the initiation of Phase III trials evaluating checkpoint inhibitors in combination with IMiDs in relapsed/refractory patients. It is still unknown why IMiDs sensitize MM cells to checkpoint inhibition, although preliminary investigations show a down-regulation of PD1 lymphocyte expression in Len treated patients which may act synergistically with anti-PD1 therapy [107]. Interestingly, a recent case report suggested that radiotherapy may also trigger response to checkpoint inhibitors. One MM patient treated within the Nivolumab phase 1 trial developed a symptomatic rib plasmocytoma for which Nivolumab was discontinued and radiation therapy initiated. After completion of radiation, Nivolumab was restarted and the patient attained a CR ongoing for 14 months [108].

Autologous tumor infiltrating lymphocytes have also been used as a therapeutic approach. It can be hypothesized that such an approach may be advantageous compared to CART or bispecifics because a polyclonal $\mathrm{T}$ cell response to individual tumor antigens may be generated. Borrello and colleagues isolated and expanded T cells from MM patients ex vivo and re-administered the cells along with an ASCT [109]. Initial experiences demonstrated the feasibility and safety of this approach, and further follow-up is awaited.

\section{NK cell based}

Apart from being the major effector for ADCC, NK cells are currently been explored as a backbone for more specific cellular immunotherapies. Analogous to the T cell approaches discussed above, autologous NK cells have been activated and expanded ex vivo and reinfused to relapsed MM patients. The procedure was safe, however in vivo proliferation did not occur [110]. Ongoing studies are aiming to increase the activity of the expanded NK cell product and increase NK cell survival in vivo. In preclinical models, CAR engineered NK 
cells specific to SLAMF7 have also shown anti-MM activity [111], and bispecific forms redirecting NK cells to tumors have been developed for other hematological cancers [112]. As for $\mathrm{T}$ cells, a class of checkpoint inhibitors specifically blocking the killer immunoglobulin-like receptor (KIR) on NK cells have been evaluated in clinical trials in MM. IPH2101, an anti-inhibitory KIR IgG4 mab, was found to be safe as a single agent as well as in combination with Lenalidomide [113, 114]. However, objective responses as a single agent were not observed. The studies investigating NK cells are more preliminary than those focusing on $\mathrm{T}$ cells, however, early results suggest the approach is feasible and larger studies analyzing clinical efficacy are underway. We will evaluate an Elotuzumab/auto SCT conditioning regimen followed by the infusion of ex vivo expanded NK cells in relapsed MM patients with high risk disease (NCT03003728).

\section{Immune Modifiers}

Interestingly, almost all novel anti-MM agents exert pleotropic effects on the patient's immune system and can be potentially used to increase the effects of targeted immune therapies. The IMiDs (e.g., Lenalidomide and Pomalidomide) are at the forefront, as they are known to propagate and activate NK cells resulting in increased ADCC [115]. Furthermore, a little understood $\mathrm{T}$ cell stimulation is also seen in vitro, an observation further supported by Len-induced graft versus host disease (GVHD) in patients after an allogeneic stem cell transplant [116-118]. Proteasome inhibitors, usually thought to be immunosuppressive rather than stimulating, can sensitize cancer cells to NK cell mediated killing by enhancing NK cell activating receptors and ligands $[119,120]$. The Bruton's tyrosine kinase inhibitor Ibrutinib, approved for CLL and Waldenstroems disease, has been shown to act synergistically with checkpoint inhibitors [121]. The alkylating agent cyclophosphamide, a backbone for various anti-MM treatments, has pleiotropic effects on the immune system including the depletion of suppressive Tregs $[122,123]$. Radiation therapy can cause inflammatory side effects, triggering the priming of adaptive anti-tumor immunity [124]. Finally, ASCT, the key element of MM treatment, exerts immunological side effects, highlighted by the autoimmune phenomena not infrequently seen in patients in the early post-transplant period [125]. In summary, these 'off target effects' of known therapies can modulate immune function and may be used in synergistic treatment combinations to augment the activity of immunotherapies.

\section{Allogeneic stem cell transplantation}

A review on immunotherapeutic advances in MM would not be complete without a discussion of the success and challenges of allogeneic (allo) SCT as well as its current role in the management of MM. Essentially, allo SCT can be considered as the prime example of immunotherapy as its activity is based on the transfer of a "new" immune system and the resulting graft-versus-myeloma $(\mathrm{GvM})$ effect. The recognition of individual tumor antigens and/or minor histocompatibility donor-recipient mismatches enables both, tailored immune responses as well as a versatile long term immune surveillance able to adapt on further tumor-antigen evolution [126]. In an ideal world, GvM would eliminate residual MM cells, and thereby prevent relapse. 
Prospective trials evaluating allo SCT in MM show conflicting results with 3 controlled studies supporting allo SCT versus 4 studies showing no outcome benefit (Table 2) [127134]. Of note, these studies were mainly conducted in the pre-novel agent era, and were not randomized as the assignment to allo SCT was based on availability of a donor. In addition, the short follow up of some studies may explain the lack of an observed survival benefit [135]. The studies clearly demonstrate that disease control can be achieved but there is a risk for treatment related mortality (10-30\%), a decrease in quality of life at least for a certain period of time and the ongoing risk of disease relapse.

Disease progression despite allo SCT challenges the concept of immunotherapy for MM. Adding to this, chronic graft versus host disease (GVHD) suggesting allo-reactivity, which is associated with a favorable outcome in other hematological malignancies, has no impact on outcome in MM [136]. This is in line with a large EBMT study highlighting plasma cell disorders to be the only hematological malignancy where GVHD does not protect from relapse [137]. Of note, reconstitution of different immune cell subsets after allo SCT occurs at different rates with neutrophils being first, followed by NK cell expansion and later by Band $T$ cell recovery [138]. T cells, which critically contribute to the GvM effect, can be suppressed for hundreds of days post allo SCT, which may be too long for some patients with highly proliferating MM $[139,140]$. We recently showed that progressive disease prior to allo SCT had the strongest negative impact on outcome underscoring the need for optimizing remission status prior to transplant [136].

Donor lymphocyte infusions (DLI), however, as an additional intervention after allo SCT, have shown remarkable responses in MM clearly demonstrating the intensification of a GvM effect [141, 142]. We and others reported a promising post transplantation strategy using pre-emptive DLI along with IMiDs and/or cyclophosphamide, and prospective trials are warranted [136, 143, 144]. A number of smaller, non-controlled allo SCT studies have also been published reporting long term survival even in patients with high risk cytogenetics [130, 134, 145-148]. The later suggests that allo SCT might be able to overcome adverse cytogenetic features, and justifies further clinical evaluation in this group of patients.

As the safety profile of allo SCT has improved over recent years, in certain circumstances, it may serve as a platform for future immunotherapy approaches potentially leading to increased tumor control by non-genotoxic means. For example, recent results from a phase I trial evaluating anti-CTLA4 Ipilimumab in patients with relapsed hematological malignancies showed clinical responses including a MM patient with pulmonary EMD, suggesting synergistic effects of novel immunotherapies in the allo setting [149].

\section{Conclusions}

Immunotherapy is a promising approach to target the genetically heterogeneous disease MM. Its mode of action primarily relies on external lysis rather than on the induction of apoptosis which is complementary to the approved standard MM therapies and is less affected by drug cross resistance. Combination chemotherapy and immune- based approaches are being integrated in all phases of MM treatment, and currently this is particularly true for the CD38 mabs. 
The future, however, appears to favor $\mathrm{T}$ cell recruiting compounds that exert a different level of tumor control. In MM the search for the best target for immunotherapy is still ongoing, however it is conceivable that in a similar approach to the treatment of actionable mutations, a customized immunotherapy approach will be taken choosing specific antigens based on the individual tumor expression. This customized approach may then be further modulated using the 'off-target' immune modulatory effects of approved anti-MM drugs. Another opportunity in immunotherapy is the ability to combine modalities; for selected patients this may include allo SCT as a platform for the novel immunotherapies to increase efficacy in patients who are not benefiting from traditional treatments. Essentially, the era of immunotherapies in MM has only just begun.

\section{Acknowledgments}

Funding:

LR is supported by the Deutsche Forschungsgemeinschaft (DFG). This work was supported in part by a grant from the National Cancer Institute, National Institutes of Health (grant number CA055819).

\section{References}

1. Morgan GJ, Walker BA, Davies FE. The genetic architecture of multiple myeloma. Nat Rev Cancer. 2012; 12(5):335-48. [PubMed: 22495321]

2. Walker BA, et al. Mutational Spectrum, Copy Number Changes, and Outcome: Results of a Sequencing Study of Patients With Newly Diagnosed Myeloma. J Clin Oncol. 2015; 33(33):391120. [PubMed: 26282654]

3. Lohr JG, et al. Widespread genetic heterogeneity in multiple myeloma: implications for targeted therapy. Cancer Cell. 2014; 25(1):91-101. [PubMed: 24434212]

4. Bolli N, et al. Heterogeneity of genomic evolution and mutational profiles in multiple myeloma. Nat Commun. 2014; 5:2997. [PubMed: 24429703]

5. Paiva B, et al. Differentiation stage of myeloma plasma cells: biological and clinical significance. Leukemia. 2016

6. Rasche L, et al. Features of extramedullary myeloma relapse: high proliferation, minimal marrow involvement, adverse cytogenetics: a retrospective single-center study of 24 cases. Ann Hematol. 2012; 91(7):1031-7. [PubMed: 22286070]

7. Pyzer AR, Avigan DE, Rosenblatt J. Clinical trials of dendritic cell-based cancer vaccines in hematologic malignancies. Hum Vaccin Immunother. 2014; 10(11):3125-31. [PubMed: 25625926]

8. Kristinsson SY, et al. Monoclonal gammopathy of undetermined significance and risk of infections: a population-based study. Haematologica. 2012; 97(6):854-8. [PubMed: 22180421]

9. Mailankody S, et al. Risk of acute myeloid leukemia and myelodysplastic syndromes after multiple myeloma and its precursor disease (MGUS). Blood. 2011; 118(15):4086-92. [PubMed: 21795746]

10. Kulkarni U, et al. IL-10 mediates plasmacytosis-associated immunodeficiency by inhibiting complement-mediated neutrophil migration. J Allergy Clin Immunol. 2016; 137(5):1487-1497 e6. [PubMed: 26653800]

11. Romano A, et al. Immunological dysregulation in multiple myeloma microenvironment. Biomed Res Int. 2014; 2014:198539. [PubMed: 25013764]

12. Noonan K, Borrello I. The immune microenvironment of myeloma. Cancer Microenviron. 2011; 4(3):313-23. [PubMed: 21866321]

13. Liu J, et al. Plasma cells from multiple myeloma patients express B7-H1 (PD-L1) and increase expression after stimulation with IFN-\{gamma $\}$ and TLR ligands via a MyD88-, TRAF6-, and MEK-dependent pathway. Blood. 2007; 110(1):296-304. [PubMed: 17363736] 
14. Prabhala RH, et al. Elevated IL-17 produced by TH17 cells promotes myeloma cell growth and inhibits immune function in multiple myeloma. Blood. 2010; 115(26):5385-92. [PubMed: 20395418]

15. Bryant $\mathrm{C}$, et al. Long-term survival in multiple myeloma is associated with a distinct immunological profile, which includes proliferative cytotoxic T-cell clones and a favourable Treg/ Th17 balance. Blood Cancer J. 2013; 3:e148. [PubMed: 24036947]

16. Muthu Raja KR, et al. Increased T regulatory cells are associated with adverse clinical features and predict progression in multiple myeloma. PLoS One. 2012; 7(10):e47077. [PubMed: 23071717]

17. Kortuem KM, et al. Activity of 129 single-agent drugs in 228 phase I and II clinical trials in multiple myeloma. Clin Lymphoma Myeloma Leuk. 2014; 14(4):284-290 e5. [PubMed: 24565465]

18. Khoo TL, et al. Interferon-alpha in the treatment of multiple myeloma. Curr Drug Targets. 2011; 12(3):437-46. [PubMed: 21143148]

19. San-Miguel J, et al. Phase 2 randomized study of bortezomib-melphalan-prednisone with or without siltuximab (anti-IL-6) in multiple myeloma. Blood. 2014; 123(26):4136-42. [PubMed: 24833354]

20. Hansson M, et al. A Phase I Dose-Escalation Study of Antibody BI-505 in Relapsed/Refractory Multiple Myeloma. Clin Cancer Res. 2015; 21(12):2730-6. [PubMed: 25712687]

21. Spencer A, et al. A phase I study of the anti-appa monoclonal antibody, MDX-1097, in previously treated multiple myeloma patients. Journal of Clinical Oncology. 2010; 28(15)

22. Kumaresan PR, et al. CS1, a novel member of the CD2 family, is homophilic and regulates NK cell function. Mol Immunol. 2002; 39(1-2):1-8. [PubMed: 12213321]

23. Tai YT, et al. Anti-CS1 humanized monoclonal antibody HuLuc63 inhibits myeloma cell adhesion and induces antibody-dependent cellular cytotoxicity in the bone marrow milieu. Blood. 2008; 112(4):1329-37. [PubMed: 17906076]

24. Hsi ED, et al. CS1, a potential new therapeutic antibody target for the treatment of multiple myeloma. Clin Cancer Res. 2008; 14(9):2775-84. [PubMed: 18451245]

25. Balasa B, et al. Elotuzumab enhances natural killer cell activation and myeloma cell killing through interleukin-2 and TNF-alpha pathways. Cancer Immunol Immunother. 2015; 64(1):61-73. [PubMed: 25287778]

26. Masood A, et al. Downregulation of BCL2 by AT-101 enhances the antileukaemic effect of lenalidomide both by an immune dependant and independent manner. Br J Haematol. 2012; 157(1):59-66. [PubMed: 22171982]

27. Zonder JA, et al. A phase 1, multicenter, open-label, dose escalation study of elotuzumab in patients with advanced multiple myeloma. Blood. 2012; 120(3):552-9. [PubMed: 22184404]

28. Lonial S, et al. Elotuzumab in combination with lenalidomide and low-dose dexamethasone in relapsed or refractory multiple myeloma. J Clin Oncol. 2012; 30(16):1953-9. [PubMed: 22547589]

29. Richardson PG, et al. Elotuzumab in combination with lenalidomide and dexamethasone in patients with relapsed multiple myeloma: final phase 2 results from the randomised, open-label, phase 1b-2 dose-escalation study. Lancet Haematol. 2015; 2(12):e516-27. [PubMed: 26686406]

30. Lonial S, et al. Elotuzumab Therapy for Relapsed or Refractory Multiple Myeloma. N Engl J Med. 2015; 373(7):621-31. [PubMed: 26035255]

31. Taylor D. Consistent Benefit Over Time in Elotuzumab Studies. Am Health Drug Benefits. 2016; 9(Spec Issue): 14 .

32. Jakubowiak AJ, et al. Phase I trial of anti-CS1 monoclonal antibody elotuzumab in combination with bortezomib in the treatment of relapsed/refractory multiple myeloma. J Clin Oncol. 2012; 30(16):1960-5. [PubMed: 22291084]

33. Palumbo A, et al. Elotuzumab Plus Bortezomib and Dexamethasone Versus Bortezomib and Dexamethasone in Patients with Relapsed/Refractory Multiple Myeloma: 2-Year Follow-up. Blood. 2015; 126(23)

34. van Rhee F, et al. Combinatorial efficacy of anti-CS1 monoclonal antibody elotuzumab (HuLuc63) and bortezomib against multiple myeloma. Mol Cancer Ther. 2009; 8(9):2616-24. [PubMed: 19723891] 
35. Usmani SZ, et al. Phase I safety data of lenalidomide, bortezomib, dexamethasone, and elotuzumab as induction therapy for newly diagnosed symptomatic multiple myeloma: SWOG S1211. Blood Cancer J. 2015; 5:e334. [PubMed: 26252787]

36. Mateos MV, et al. Elotuzumab in combination with thalidomide and low-dose dexamethasone: a phase 2 single-arm safety study in patients with relapsed/refractory multiple myeloma. Br J Haematol. 2016

37. Lisenko K, et al. Potential therapeutic targets in plasma cell disorders: A flow cytometry study. Cytometry B Clin Cytom. 2015

38. Jakubowiak A, et al. Randomized phase 2 study: elotuzumab plus bortezomib/dexamethasone vs bortezomib/dexamethasone for relapsed/refractory MM. Blood. 2016; 127(23):2833-40. [PubMed: 27091875]

39. Lokhorst HM, et al. Targeting CD38 with Daratumumab Monotherapy in Multiple Myeloma. N Engl J Med. 2015; 373(13):1207-19. [PubMed: 26308596]

40. Maloney DG, et al. IDEC-C2B8 (Rituximab) anti-CD20 monoclonal antibody therapy in patients with relapsed low-grade non-Hodgkin's lymphoma. Blood. 1997; 90(6):2188-95. [PubMed: 9310469]

41. Lonial S, et al. Daratumumab monotherapy in patients with treatment-refractory multiple myeloma (SIRIUS): an open-label, randomised, phase 2 trial. Lancet. 2016; 387(10027):1551-60. [PubMed: 26778538]

42. de Weers M, et al. Daratumumab, a novel therapeutic human CD38 monoclonal antibody, induces killing of multiple myeloma and other hematological tumors. J Immunol. 2011; 186(3):1840-8. [PubMed: 21187443]

43. Krejcik J, et al. Immunomodulatory Effects and Adaptive Immune Response to Daratumumab in Multiple Myeloma. Blood. 2015; 126(23)

44. Overdijk MB, et al. Antibody-mediated phagocytosis contributes to the anti-tumor activity of the therapeutic antibody daratumumab in lymphoma and multiple myeloma. MAbs. 2015; 7(2):31121. [PubMed: 25760767]

45. Krejcik J, et al. Daratumumab depletes CD38+ immune-regulatory cells, promotes T-cell expansion, and skews T-cell repertoire in multiple myeloma. Blood. 2016

46. Atanackovic D, et al. Chimeric Antigen Receptor (CAR) therapy for multiple myeloma. Br J Haematol. 2016; 172(5):685-98. [PubMed: 26791002]

47. Mehta K, Shahid U, Malavasi F. Human CD38, a cell-surface protein with multiple functions. FASEB J. 1996; 10(12):1408-17. [PubMed: 8903511]

48. Casneuf T, et al. Pharmacodynamic Relationship between Natural Killer Cells and Daratumumab Exposure in Relapsed/Refractory Multiple Myeloma. Haematologica. 2016; 101:87-88.

49. Martin T, et al. A Phase I Trial of Sar650984, a Cd38 Monoclonal Antibody, in Relapsed or Refractory Multiple Myeloma. Haematologica. 2014; 99:519-519. [PubMed: 24241489]

50. Mateos MV, et al. An Open-Label, Multicenter, Phase 1b Study of Daratumumab in Combination with Pomalidomide-Dexamethasone and with Backbone Regimens in Patients with Multiple Myeloma. Haematologica. 2015; 100:84-84.

51. Plesner T, et al. Daratumumab in Combination with Lenalidomide and Dexamethasone in Patients with Relapsed or Relapsed and Refractory Multiple Myeloma: Updated Results of a Phase 1/2 Study (GEN503). Blood. 2015; 126(23)

52. Dimopoulos MA, et al. Daratumumab, Lenalidomide, and Dexamethasone for Multiple Myeloma. N Engl J Med. 2016; 375(14):1319-1331. [PubMed: 27705267]

53. Palumbo A, et al. Daratumumab, Bortezomib, and Dexamethasone for Multiple Myeloma. N Engl J Med. 2016; 375(8):754-66. [PubMed: 27557302]

54. Perez-Andres M, et al. Clonal plasma cells from monoclonal gammopathy of undetermined significance, multiple myeloma and plasma cell leukemia show different expression profiles of molecules involved in the interaction with the immunological bone marrow microenvironment. Leukemia. 2005; 19(3):449-55. [PubMed: 15674420]

55. Nijhof IS, et al. Upregulation of CD38 expression on multiple myeloma cells by all-trans retinoic acid improves the efficacy of daratumumab. Leukemia. 2015; 29(10):2039-49. [PubMed: 25975191] 
56. Nijhof IS, et al. CD38 expression and complement inhibitors affect response and resistance to daratumumab therapy in myeloma. Blood. 2016; 128(7):959-70. [PubMed: 27307294]

57. Nijhof I, et al. Expression Levels of Cd38 and Complement Inhibitory Proteins Cd55 and Cd59 Predict Response to Daratumumab in Multiple Myeloma. Haematologica. 2015; 100:175-176.

58. de Haart SJ, et al. Sepantronium bromide (YM155) improves daratumumab-mediated cellular lysis of multiple myeloma cells by abrogation of bone marrow stromal cell-induced resistance. Haematologica. 2016; 101(8):e339-42. [PubMed: 27151995]

59. Mraz M, et al. Bone marrow stromal cells protect lymphoma B-cells from rituximab-induced apoptosis and targeting integrin alpha-4-beta-1 (VLA-4) with natalizumab can overcome this resistance. Br J Haematol. 2011; 155(1):53-64. [PubMed: 21749361]

60. Tembhare P, et al. Antigenic drift in relapsed extramedullary multiple myeloma: plasma cells without CD38 expression. Leukemia \& Lymphoma. 2012; 53(4):721-724. [PubMed: 21942285]

61 . Bensinger $\mathrm{W}$, et al. A phase 1 study of lucatumumab, a fully human anti-CD40 antagonist monoclonal antibody administered intravenously to patients with relapsed or. refractory multiple myeloma. Br J Haematol. 2012; 159(1):58-66. [PubMed: 22861192]

62. Heffner LT, et al. BT062, an Antibody-Drug Conjugate Directed Against CD138, Given Weekly for 3 Weeks in Each 4 Week Cycle: Safety and Further Evidence of Clinical Activity. Blood. 2012; 120(21)

63. Berdeja JG. Lorvotuzumab mertansine: antibody-drug-conjugate for CD56+ multiple myeloma. Front Biosci (Landmark Ed). 2014; 19:163-70. [PubMed: 24389179]

64. Kelly KR, et al. Indatuximab Ravtansine (BT062) In Combination With Lenalidomide and LowDose Dexamethasone In Patients With Relapsed and/Or Refractory Multiple Myeloma: Clinical Activity In Len/Dex-Refractory Patients. Blood. 2013; 122(21)

65. Tai YT, et al. Novel anti-B-cell maturation antigen antibody-drug conjugate (GSK2857916) selectively induces killing of multiple myeloma. Blood. 2014; 123(20):3128-38. [PubMed: 24569262]

66. Lee L, et al. Evaluation of B cell maturation antigen as a target for antibody drug conjugate mediated cytotoxicity in multiple myeloma. Br J Haematol. 2016

67. Gish K, et al. Preclinical Evaluation of Abbv-838, a First-in-Class Anti-Cs1 Antibody-Drug Conjugate for the Treatment of Multiple Myeloma. Haematologica. 2016; 101:253-253.

68. van Rhee F. Engineering more efficacious antibody therapy for myeloma. Blood. 2014; 123(20): 3062-3. [PubMed: 24832938]

69. Rasche L, et al. A GRP78-directed monoclonal antibody recaptures response in refractory multiple myeloma with extramedullary involvement. Clin Cancer Res. 2016

70. Rasche L, et al. GRP78-directed immunotherapy in relapsed or refractory multiple myeloma results from a phase 1 trial with the monoclonal immunoglobulin M antibody PAT-SM6. Haematologica. 2015; 100(3):377-84. [PubMed: 25637055]

71. Rotolo A, Caputo V, Karadimitris A. The prospects and promise of chimeric antigen receptor immunotherapy in multiple myeloma. Br J Haematol. 2016; 173(3):350-64. [PubMed: 26953076]

72. Morgan RA, et al. Case report of a serious adverse event following the administration of $\mathrm{T}$ cells transduced with a chimeric antigen receptor recognizing ERBB2. Mol Ther. 2010; 18(4):843-51. [PubMed: 20179677]

73. Linette GP, et al. Cardiovascular toxicity and titin cross-reactivity of affinity-enhanced $\mathrm{T}$ cells in myeloma and melanoma. Blood. 2013; 122(6):863-71. [PubMed: 23770775]

74. Walz S, et al. The antigenic landscape of multiple myeloma: mass spectrometry (re)defines targets for T-cell-based immunotherapy. Blood. 2015; 126(10):1203-13. [PubMed: 26138685]

75. Maude SL, et al. Chimeric antigen receptor T cells for sustained remissions in leukemia. N Engl J Med. 2014; 371(16):1507-17. [PubMed: 25317870]

76. Kochenderfer JN, et al. Chemotherapy-refractory diffuse large B-cell lymphoma and indolent Bcell malignancies can be effectively treated with autologous $\mathrm{T}$ cells expressing an anti-CD19 chimeric antigen receptor. J Clin Oncol. 2015; 33(6):540-9. [PubMed: 25154820]

77. Rawstron AC, et al. Report of the European Myeloma Network on multiparametric flow cytometry in multiple myeloma and related disorders. Haematologica. 2008; 93(3):431-8. [PubMed: 18268286] 
78. Mateo G, et al. Prognostic value of immunophenotyping in multiple myeloma: a study by the PETHEMA/GEM cooperative study groups on patients uniformly treated with high-dose therapy. $\mathrm{J}$ Clin Oncol. 2008; 26(16):2737-44. [PubMed: 18443352]

79. Hudecek M, Einsele H. Myeloma CARs are rolling into the clinical arena. Blood. 2016; 128(13): 1667-8. [PubMed: 27688779]

80. Garfall AL, et al. Chimeric Antigen Receptor T Cells against CD19 for Multiple Myeloma. N Engl J Med. 2015; 373(11):1040-7. [PubMed: 26352815]

81. Garfall AL, et al. Safety and efficacy of anti-CD19 chimeric antigen receptor (CAR)-modified autologous T cells (CTL019) in advanced multiple myeloma. Journal of Clinical Oncology. 2015; 33(15)

82. Davila ML, et al. Efficacy and toxicity management of $19-28 z$ CAR T cell therapy in B cell acute lymphoblastic leukemia. Sci Transl Med. 2014; 6(224):224ra25.

83. Maude SL, et al. CD19-targeted chimeric antigen receptor T-cell therapy for acute lymphoblastic leukemia. Blood. 2015; 125(26):4017-23. [PubMed: 25999455]

84. Xu XJ, Tang YM. Cytokine release syndrome in cancer immunotherapy with chimeric antigen receptor engineered T cells. Cancer Lett. 2014; 343(2):172-8. [PubMed: 24141191]

85. Ali SA, et al. Remissions of Multiple Myeloma during a First-in-Humans Clinical Trial of T Cells Expressing an Anti-B-Cell Maturation Antigen Chimeric Antigen Receptor. Blood. 2015; 126(23)

86. Ali SA, et al. T cells expressing an anti-B-cell maturation antigen chimeric antigen receptor cause remissions of multiple myeloma. Blood. 2016; 128(13):1688-700. [PubMed: 27412889]

87. Ramos CA, et al. Clinical responses with $\mathrm{T}$ lymphocytes targeting malignancy-associated kappa light chains. J Clin Invest. 2016; 126(7):2588-96. [PubMed: 27270177]

88. Rapoport AP, et al. NY-ESO-1-specific TCR-engineered T cells mediate sustained antigen-specific antitumor effects in myeloma. Nat Med. 2015; 21(8):914-21. [PubMed: 26193344]

89. Drent E, et al. Pre-clinical evaluation of CD38 chimeric antigen receptor engineered T cells for the treatment of multiple myeloma. Haematologica. 2016; 101(5):616-25. [PubMed: 26858358]

90. Chu J, et al. Genetic modification of T cells redirected toward CS1 enhances eradication of myeloma cells. Clin Cancer Res. 2014; 20(15):3989-4000. [PubMed: 24677374]

91. Topp MS, et al. Safety and activity of blinatumomab for adult patients with relapsed or refractory B-precursor acute lymphoblastic leukaemia: a multicentre, single-arm, phase 2 study. Lancet Oncol. 2015; 16(1):57-66. [PubMed: 25524800]

92. Kantarjian HM, et al. Blinatumomab treatment of older adults with relapsed/refractory B-precursor acute lymphoblastic leukemia: Results from two phase 2 studies. Cancer. 2016

93. Duell J, et al. Frequency of regulatory T cells determines the outcome of the T-cell-engaging antibody blinatumomab in patients with B-precursor ALL. Leukemia. 2017

94. Dull J, et al. Functional Defects of T Cells of Lymphoma Patients after Different Chemotherapy Regimens Activated by the Bispecific Antibody Afm11. Haematologica. 2015; 100:543-544.

95. Carpenter RO, et al. B-cell maturation antigen is a promising target for adoptive T-cell therapy of multiple myeloma. Clin Cancer Res. 2013; 19(8):2048-60. [PubMed: 23344265]

96. Ramadoss NS, et al. An anti-B cell maturation antigen bispecific antibody for multiple myeloma. J Am Chem Soc. 2015; 137(16):5288-91. [PubMed: 25826669]

97. Hipp S, et al. BI 836909, a Novel Bispecific T Cell Engager for the Treatment of Multiple Myeloma Induces Highly Specific and Efficacious Lysis of Multiple Myeloma Cells in Vitro and Shows Anti-Tumor Activity in Vivo. Blood. 2015; 126(23)

98. Moore GL, et al. Tuning T Cell Affinity Improves Efficacy and Safety of Anti-CD38 x Anti-CD3 Bispecific Antibodies in Monkeys - a Potential Therapy for Multiple Myeloma. Blood. 2015; 126(23)

99. Zou J, et al. Immunotherapy based on bispecific T-cell engager with hIgG1 Fc sequence as a new therapeutic strategy in multiple myeloma. Cancer Sci. 2015; 106(5):512-21. [PubMed: 25664501]

100. Lum LG, et al. Induction Of Anti-Myeloma Cellular and Humoral Immunity By Pre-Targeting Clonogenic Myeloma Cells Prior To Stem Cell Transplant With T Cells Armed With Anti-CD3 x Anti-CD20 Bispecific Antibody Leads To Transfer Of Cellular and Hum oral Anti-Myeloma Immunity. Blood. 2013; 122(21) 
101. Honemann D, et al. A novel recombinant bispecific single-chain antibody, bscWue-1 x CD3, induces T-cell-mediated cytotoxicity towards human multiple myeloma cells. Leukemia. 2004; 18(3):636-44. [PubMed: 14737072]

102. Paiva B, et al. PD-L1/PD-1 presence in the tumor microenvironment and activity of PD-1 blockade in multiple myeloma. Leukemia. 2015; 29(10):2110-3. [PubMed: 25778100]

103. Topalian SL, et al. Safety, activity, and immune correlates of anti-PD-1 antibody in cancer. N Engl J Med. 2012; 366(26):2443-54. [PubMed: 22658127]

104. Lesokhin AM, et al. Preliminary Results of a Phase I Study of Nivolumab (BMS-936558) in Patients with Relapsed or Refractory Lymphoid Malignancies. Blood. 2014; 124(21)

105. San Miguel J, et al. Pembrolizumab in Combination with Lenalidomide and Low-Dose Dexamethasone for Relapsed/Refractory Multiple Myeloma (RRMM): Keynote-023. Blood. 2015; 126(23)

106. Badros AZ, et al. A Phase II Study of Anti PD-1 Antibody Pembrolizumab, Pomalidomide and Dexamethasone in Patients with Relapsed/Refractory Multiple Myeloma (RRMM). Blood. 2015; 126(23)

107. Danhof S, et al. Impact of Lenalidomide on T cell subset composition and PD-1 phenotype in patients with multiple myeloma. Oncology Research and Treatment. 2015; 38:234-234.

108. Lesokhin AM, et al. Nivolumab in Patients With Relapsed or Refractory Hematologic Malignancy: Preliminary Results of a Phase Ib Study. J Clin Oncol. 2016; 34(23):2698-704. [PubMed: 27269947]

109. Noonan KA, et al. Adoptive transfer of activated marrow-infiltrating lymphocytes induces measurable antitumor immunity in the bone marrow in multiple myeloma. Sci Transl Med. 2015; 7(288):288ra78.

110. Szmania $S$, et al. Ex vivo-expanded natural killer cells demonstrate robust proliferation in vivo in high-risk relapsed multiple myeloma patients. J Immunother. 2015; 38(1):24-36. [PubMed: 25415285]

111. Chu J, et al. CS1-specific chimeric antigen receptor (CAR)-engineered natural killer cells enhance in vitro and in vivo antitumor activity against human multiple myeloma. Leukemia. 2014; 28(4): 917-27. [PubMed: 24067492]

112. Reusch U, et al. A tetravalent bispecific TandAb (CD19/CD3), AFM11, efficiently recruits T cells for the potent lysis of CD19(+) tumor cells. MAbs. 2015; 7(3):584-604. [PubMed: 25875246]

113. Benson DM Jr, et al. A Phase I Trial of the Anti-KIR Antibody IPH2101 and Lenalidomide in Patients with Relapsed/Refractory Multiple Myeloma. Clin Cancer Res. 2015; 21(18):4055-61. [PubMed: 25999435]

114. Benson DM Jr, et al. A phase 1 trial of the anti-KIR antibody IPH2101 in patients with relapsed/ refractory multiple myeloma. Blood. 2012; 120(22):4324-33. [PubMed: 23033266]

115. Davies FE, et al. Thalidomide and immunomodulatory derivatives augment natural killer cell cytotoxicity in multiple myeloma. Blood. 2001; 98(1):210-6. [PubMed: 11418482]

116. Haslett PA, et al. Thalidomide and a thalidomide analogue drug costimulate virus-specific CD8+ T cells in vitro. J Infect Dis. 2003; 187(6):946-55. [PubMed: 12660941]

117. Alsina $\mathrm{M}$, et al. Lenalidomide maintenance for high-risk multiple myeloma after allogeneic hematopoietic cell transplantation. Biol Blood Marrow Transplant. 2014; 20(8):1183-9. [PubMed: 24769014]

118. Kramer I, et al. Lenalidomide enhances myeloma-specific T-cell responses in vivo and in vitro. Oncoimmunology. 2016; 5(5):e1139662. [PubMed: 27467960]

119. Pellom ST Jr, et al. Modulatory effects of bortezomib on host immune cell functions. Immunotherapy. 2015; 7(9):1011-22. [PubMed: 26325610]

120. Shi J, et al. Bortezomib down-regulates the cell-surface expression of HLA class I and enhances natural killer cell-mediated lysis of myeloma. Blood. 2008; 111(3):1309-17. [PubMed: 17947507]

121. Sagiv-Barfi I, et al. Therapeutic antitumor immunity by checkpoint blockade is enhanced by ibrutinib, an inhibitor of both BTK and ITK. Proc Natl Acad Sci U S A. 2015; 112(9):E966-72. [PubMed: 25730880] 
122. Brode S, Cooke A. Immune-potentiating effects of the chemotherapeutic drug cyclophosphamide. Crit Rev Immunol. 2008; 28(2):109-26. [PubMed: 18540827]

123. Zou W. Regulatory T cells, tumour immunity and immunotherapy. Nat Rev Immunol. 2006; 6(4): 295-307. [PubMed: 16557261]

124. Scheithauer H, et al. Immunological aspects of radiotherapy. Radiat Oncol. 2014; 9:185. [PubMed: 25142149]

125. Hequet $\mathrm{O}$, et al. Autoimmune thrombocytopenic purpura after autologous stem cell transplantation. Bone Marrow Transplant. 2003; 32(1):89-95. [PubMed: 12815483]

126. Schieferdecker A, et al. A transplant "immunome" screening platform defines a targetable epitope fingerprint of multiple myeloma. Blood. 2016; 127(25):3202-14. [PubMed: 27034429]

127. Garban F, et al. Prospective comparison of autologous stem cell transplantation followed by dosereduced allograft (IFM99-03 trial) with tandem autologous stem cell transplantation (IFM99-04 trial) in high-risk de novo multiple myeloma. Blood. 2006; 107(9):3474-80. [PubMed: 16397129]

128. Rosinol L, et al. A prospective PETHEMA study of tandem autologous transplantation versus autograft followed by reduced-intensity conditioning allogeneic transplantation in newly diagnosed multiple myeloma. Blood. 2008; 112(9):3591-3. [PubMed: 18612103]

129. Bjorkstrand B, et al. Tandem autologous/reduced-intensity conditioning allogeneic stem-cell transplantation versus autologous transplantation in myeloma: long-term follow-up. J Clin Oncol. 2011; 29(22):3016-22. [PubMed: 21730266]

130. Knop S, et al. Autologous Followed By Allogeneic Versus TandemAutologous Stem Cell Transplant in Newly Diagnosed FISH-del13q Myeloma. Blood. 2014; 124(21)

131. Bruno B, et al. A comparison of allografting with autografting for newly diagnosed myeloma. $\mathrm{N}$ Engl J Med. 2007; 356(11):1110-20. [PubMed: 17360989]

132. Krishnan A, et al. Autologous haemopoietic stem-cell transplantation followed by allogeneic or autologous haemopoietic stem-cell transplantation in patients with multiple myeloma (BMT CTN 0102): a phase 3 biological assignment trial. Lancet Oncol. 2011; 12(13):1195-203. [PubMed: 21962393]

133. Lokhorst HM, et al. Donor versus no-donor comparison of newly diagnosed myeloma patients included in the HOVON-50 multiple myeloma study. Blood. 2012; 119(26):6219-25. quiz 6399. [PubMed: 22442350]

134. Gertz MA. When to recommend allogeneic transplant in multiple myeloma. Leuk Lymphoma. 2015; 56(9):2512-7. [PubMed: 25989864]

135. Gahrton G, Krishnan A. Allogeneic transplantation in multiple myeloma. Expert Rev Hematol. 2014; 7(1):79-90. [PubMed: 24224804]

136. Rasche L, et al. Allogeneic Hematopoietic Cell Transplantation in Multiple Myeloma: Focus on Longitudinal Assessment of Donor Chimerism, Extramedullary Disease and High Risk Cytogenetic Features. Biol Blood Marrow Transplant. 2016

137. Stern M, et al. Sensitivity of hematological malignancies to graft-versus-host effects: an EBMT megafile analysis. Leukemia. 2014; 28(11):2235-40. [PubMed: 24781016]

138. Seggewiss R, Einsele H. Immune reconstitution after allogeneic transplantation and expanding options for immunomodulation: an update. Blood. 2010; 115(19):3861-8. [PubMed: 20215642]

139. Storek J, et al. Immunity of patients surviving 20 to 30 years after allogeneic or syngeneic bone marrow transplantation. Blood. 2001; 98(13):3505-12. [PubMed: 11739150]

140. Williams KM, Gress RE. Immune reconstitution and implications for immunotherapy following haematopoietic stem cell transplantation. Best Pract Res Clin Haematol. 2008; 21(3):579-96. [PubMed: 18790456]

141. Lokhorst HM, et al. Donor lymphocyte infusions for relapsed multiple myeloma after allogeneic stem-cell transplantation: predictive factors for response and long-term outcome. J Clin Oncol. 2000; 18(16):3031-7. [PubMed: 10944138]

142. Alyea E, et al. T-cell--depleted allogeneic bone marrow transplantation followed by donor lymphocyte infusion in patients with multiple myeloma: induction of graft-versus-myeloma effect. Blood. 2001; 98(4):934-9. [PubMed: 11493435] 
143. Michallet M, et al. Evolving strategies with immunomodulating drugs and tandem autologous/ allogeneic hematopoietic stem cell transplantation in first line high risk multiple myeloma patients. Exp Hematol. 2013; 41(12):1008-15. [PubMed: 23994781]

144. Beitinjaneh AM, et al. Durable responses after donor lymphocyte infusion for patients with residual multiple myeloma following non-myeloablative allogeneic stem cell transplant. Leuk Lymphoma. 2012; 53(8):1525-9. [PubMed: 22242817]

145. Kroger N, et al. Impact of high-risk cytogenetics and achievement of molecular remission on long-term freedom from disease after autologous-allogeneic tandem transplantation in patients with multiple myeloma. Biol Blood Marrow Transplant. 2013; 19(3):398-404. [PubMed: 23078786]

146. Festuccia M, et al. Allogeneic stem cell transplantation in multiple myeloma: immunotherapy and new drugs. Expert Opin Biol Ther. 2015; 15(6):857-72. [PubMed: 25865214]

147. Franssen LE, et al. Outcome of allogeneic transplantation in newly diagnosed and relapsed/ refractory multiple myeloma: long-term follow-up in a single institution. Eur J Haematol. 2016

148. Ahmad I, et al. Favorable long-term outcome of patients with multiple myeloma using a frontline tandem approach with autologous and non-myeloablative allogeneic transplantation. Bone Marrow Transplant. 2016; 51(4):529-35. [PubMed: 26691426]

149. Davids MS, et al. Ipilimumab for Patients with Relapse after Allogeneic Transplantation. N Engl J Med. 2016; 375(2):143-53. [PubMed: 27410923]

150. Gahrton G, et al. Autologous/reduced-intensity allogeneic stem cell transplantation vs autologous transplantation in multiple myeloma: long-term results of the EBMT-NMAM2000 study. Blood. 2013; 121(25):5055-63. [PubMed: 23482933] 


\section{Highlights}

- The monoclonal antibodies Daratumumab and Elotuzumab have shown antiMM activity in randomized trials

- $\quad$ CAR T cells targeting CD19 or BCMA have induced responses in heavily pretreated patients

- $\quad$ Bispecific antibodies targeting both tumor and immune cells are currently being evaluated in phase 1 trials

- Checkpoint inhibitors in combination with IMiDs show responses in relapse refractory patients leading to phase III trials

- The side effect profile of immune based approaches are different to standard chemotherapeutic approaches and need careful monitoring

- Allogeneic stem cell transplantation, may be a platform for novel immunotherapies in selected patients

- $\quad$ Personalized immunotherapy approaches which account for both the individual patient' $s$ tumor immune phenotype as well as the patient' $\mathrm{s}$ immune effector cell status may result in long term disease control and cure 


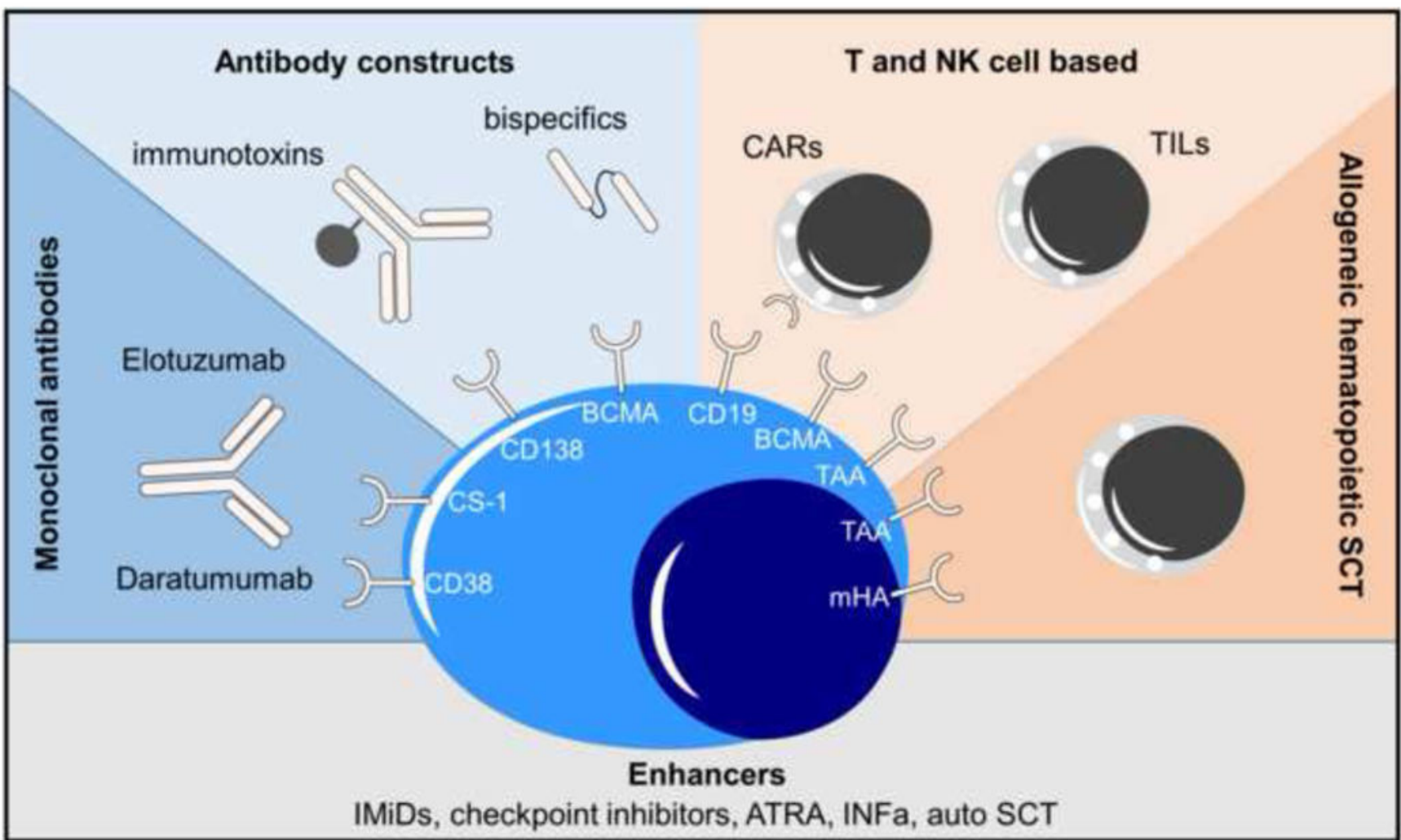

Figure 1.

Current strategies using immunologic components to treat multiple myeloma. Abbrs: CARs:

Chimeric antigen receptor T cells; TILs: Tumor infiltrating lymphocytes; IMiDs:

Immunomodulatory drugs; ATRA: all trans retinoic acid; INFa: Interferon alfa; auto: autologous; SCT stem cell transplantation 


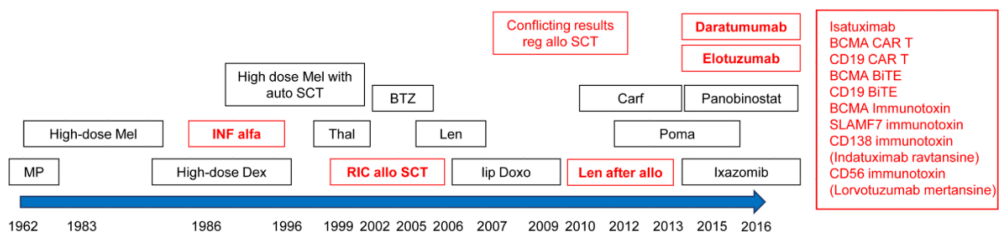

Figure 2.

History of immunotherapeutic approaches in MM (marked in red). Abbr: Mel - Melphalan, MP - Melphalan/Prednisone, INF - Interferon, Dex - Dexamethasone, Thal - Thalidomide, BTZ - Bortezomib, RIC allo SCT - reduced intensity allogeneic stem cell transplantation, lip Doxo - liposomal Doxorubicin, Carf - Carfilzomib, Len - Lenalidomide, Poma Pomalidomide 


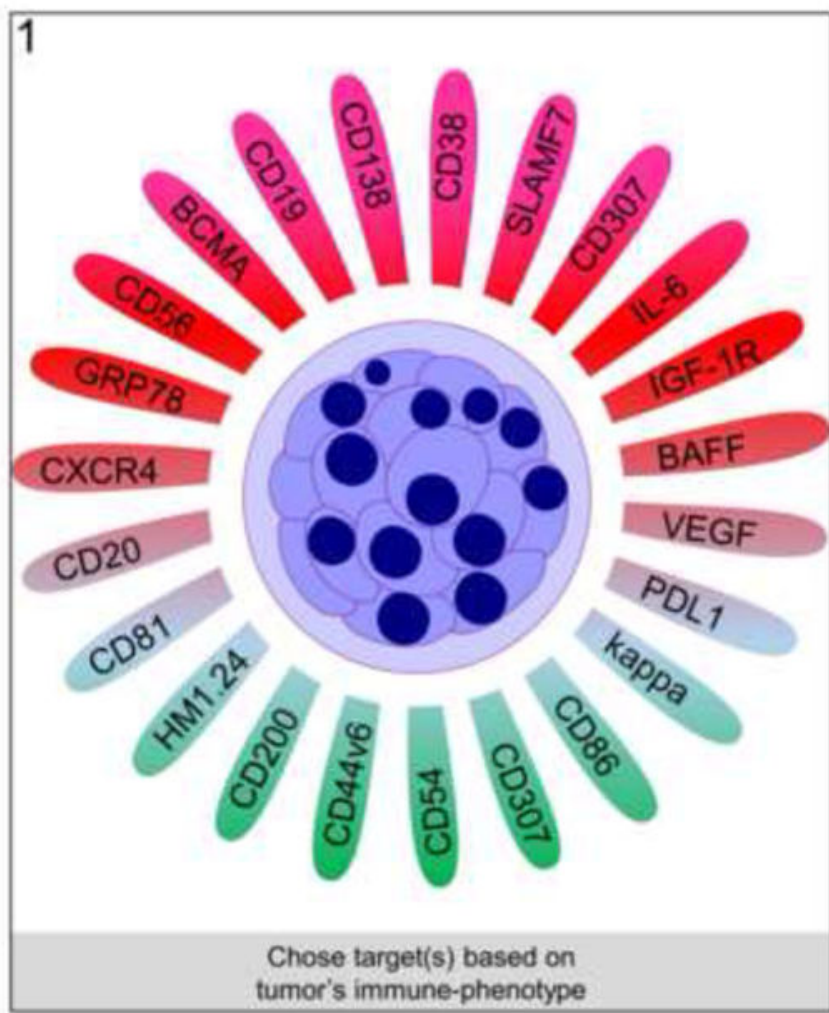
tumor's immune-phenotype
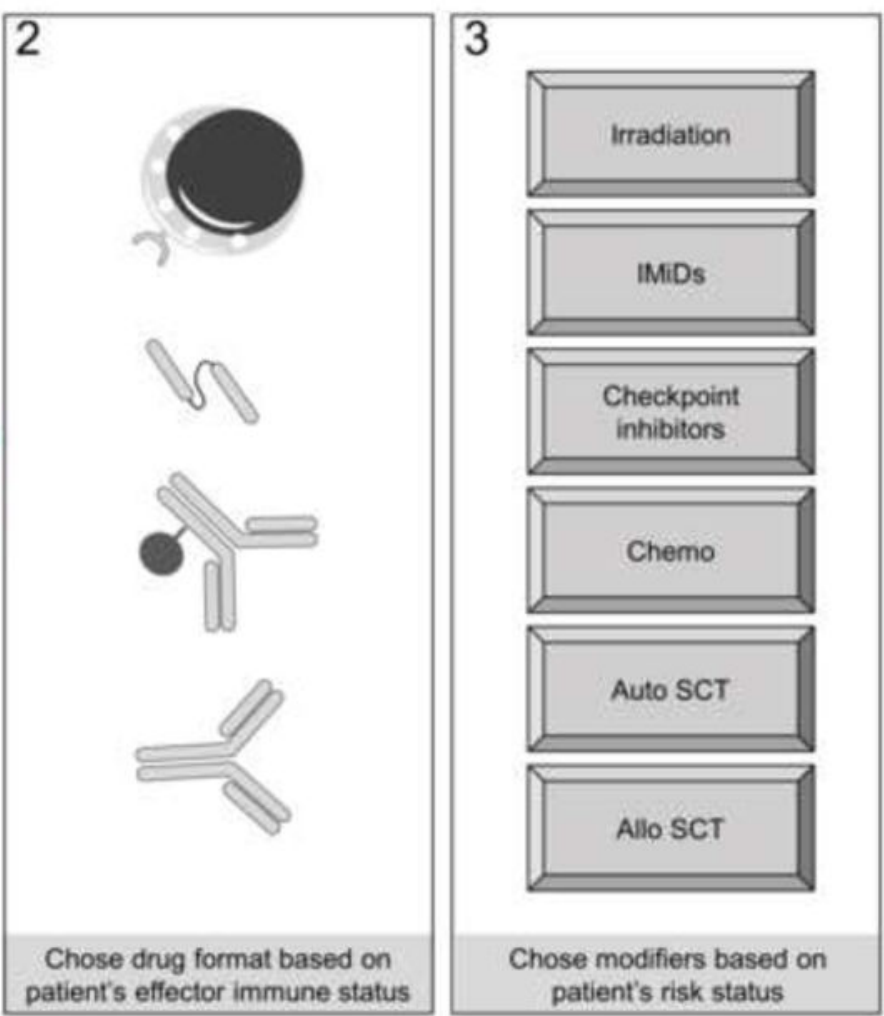

Figure 3.

A proposed personalized immunotherapy for MM. Abbr: IMiDs: Immunomodulating drugs; auto: autologous; SCT: stem cell transplantation, allo: allogeneic 


\section{Table 1}

Ongoing trials investigating Daratumumab or Elotuzumab in multiple myeloma (updated Nov 2016)

\begin{tabular}{|l|l|l|l|l|}
\hline Smoldering MM & $\begin{array}{l}\text { 1. Line Tx eligible } \\
\text { 1. Line Tx-non eligible }\end{array}$ & Maintenance & Early relapse & Relapsed-Refractory \\
\hline Dara single agent $\mathbf{R}$ & Dara + multi combo $\mathbf{R}$ & Dara + Vel/Thal/Dex & Dara Rd $\mathbf{R}$ & Dara single agent \\
\hline Elo +Rd & Dara + Vel/Thal/Dex $\mathbf{R}$ & Elo-Len & Dara Vel/dex $\mathbf{R}$ & Dara multi combo \\
\hline Elo +VRD R & Dara + Rd $\mathbf{R}$ & Elo +VRD R & Elo +Vel/Dex R & Dara s.c. \\
\hline & Dara + VMP $\mathbf{R}$ & & & Elo +Thal/Dex \\
\hline & Elo +VRD R & & & Elo +Vel/Dex $\mathbf{R}$ \\
\hline & Elo +Rd $\mathbf{R}$ & & & Elo +Pom/Dex $\mathbf{R}$ \\
\hline & & & & Elo +Pom/Vel/Dex \\
\hline & & & & Elo +Nivo/Pom/Dex $\mathbf{R}$ \\
\hline
\end{tabular}

Abbreviations: R - randomized trial, Tx - therapy, Dara - Daratumumab, Elo - Elotuzumab, Vel - Bortezomib, Thal - Thalidomide, Dex -

Dexamethasone, Rd - Lenalidomide/dexamethasone, Pom - Pomalidomide, Nivo - Nivolumab, s.c. subcutaneous 


\section{Table 2}

Prospective trials evaluated allogeneic stem cell transplantation as part of the first line treatment of MM

\begin{tabular}{|l|l|l|l|}
\hline YEAR & Design & Novel agents used & Results favoring allo \\
\hline Bruno B et al, 2007 NEJM [131] & Auto-Auto vs Auto- Allo & no & Yes \\
\hline Krishan et al, 2011 Lancet Oncology [132] & Auto-Auto vs. Auto- & Thal maintainance & No \\
\hline Lokhorst 2012 Blood [133] & Allo Auto-Auto vs Auto Allo & Thal induction & No \\
\hline Garban et al, 2006 Blood [127] & Auto-Auto vs. Auto- allo & no & No \\
\hline $\begin{array}{l}\text { Bjorkstrand B et al 2011 JCO [129] } \\
\text { Updated by Gahrton et al., 2013 Blood [150] }\end{array}$ & Auto-Auto vs Auto- Allo & no & Yes \\
\hline Rosinol L et al, 2008 Blood [128] & Auto-auto vs auto- allo & no & No \\
\hline Knop, S ASH 2014 [130] & Auto-auto vs auto- allo in del13q & no & Yes \\
\hline
\end{tabular}

